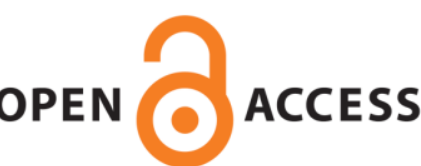

UWS Academic Portal

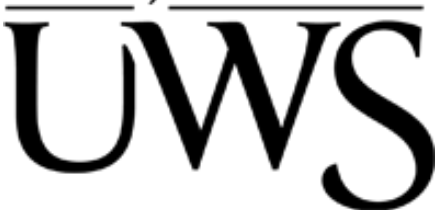

\title{
Knowledge and skills needed by informal carers to look after terminally ill patients at home
}

Connolly, Josaleen; Milligan, Stuart

Published in:

End of Life Journal

Published: 01/01/2014

Document Version

Publisher's PDF, also known as Version of record

Link to publication on the UWS Academic Portal

Citation for published version (APA):

Connolly, J., \& Milligan, S. (2014). Knowledge and skills needed by informal carers to look after terminally ill patients at home. End of Life Journal, 4(2), 1-14.

\section{General rights}

Copyright and moral rights for the publications made accessible in the UWS Academic Portal are retained by the authors and/or other copyright owners and it is a condition of accessing publications that users recognise and abide by the legal requirements associated with these rights.

Take down policy

If you believe that this document breaches copyright please contact pure@uws.ac.uk providing details, and we will remove access to the work immediately and investigate your claim. 


\section{KNOWLEDGE AND SKILLS NEEDED BY INFORMAL CARERS TO LOOK AFTER TERMINALLY ILL PATIENTS AT HOME}

\section{Josaleen Connolly, Dr Stuart Milligan}

\section{KEY WORDS}

Education and support

Informal carers

Palliative and end-of-life care Place of death

Symptom management

Josaleen Connolly, Clinical Improvement

Practitioner, Cancer and Palliative Care, NHS

Ayrshire \& Arran, Ailsa Hospital, Ayr,

and Dr Stuart Milligan, Lecturer, School of Health, Nursing and Midwifery, University of the West of Scotland, and Education Facilitator, Ardgowan Hospice, Greenock. Emails: Josaleen.Connolly@ aapct.scot.nhs.uk; stuart.milligan@uws.ac.uk

$\mathrm{P}$ eople with life-limiting conditions are living longer than previously due to better treatment and management (Department of Health, 2008). This places a significant burden on the NHS to provide adequate care as the person's disease progresses (Stajduhar, 2003; Department of Health, 2008). The majority of people die in hospital (O'Brien and Jack, 20 I0; Gao et al, 20।3). However, in the later stages of life, many people would prefer to be at home surrounded by their family and friends, with support from their local community services, i.e. community nursing, GPs, and palliative care and social work teams (Thomas et al, 2004; Stajduhar and Davies, 2005; Beccaro et al, 2006; Heyland et al, 2006; Gomes et al, 20।3).

The factors that are associated with where death occurs include

\section{Abstract}

Background: The majority of terminally ill people wish to remain, and be cared for, at home by family members with the support of the community care team. However, informal carers tend to feel unprepared for the caring role, are often elderly, have varying levels of support and suffer stress and anxiety as a result of the role. Aim and objectives: The aim of this study was to explore the lived experiences of informal carers providing care for an adult receiving palliative care at home. To that end it explored carers' experiences about what they need to know in order to provide care and the practical skills that carers believe they need for their role. Methods: A qualitative research design was employed, using an interpretative phenomenological approach. Semistructured interviews were conducted, digitally recorded and transcribed verbatim. A thematic content analysis method was adopted for analysing interview transcripts. Results: A total of six interviews were conducted with eight bereaved participants (three participants were from the same family and did a joint interview). Two main themes emerged from the data, with associated subthemes: (I) knowing the right thing to do (subthemes: need for knowledge and practical skills; managing symptoms and administering medications; knowing what is best for the person); (2) personal experiences of caring (subthemes: impact of caring on health; the need to accept help; and experiencing a sense of satisfaction). Participants suggested that carers require adequate preparation for the caring role, in terms of the necessary skills, the provision of timely information and knowledge, assessment and provision of practical and emotional support. Conclusions: Carers need specific knowledge and skills at different points over the duration of their role. Ultimately, carers need to know that they are doing the right thing and that appropriate help and guidance will be available if they need it. Adequate support should result in the experience of caring for a loved one with palliative care needs at home being improved. Conflicts of interest: none

the patient's functional status, patient preference, living with relatives, extended family support, as well as the availability, level and quality of health care in the community setting (Gomes and Higginson, 2006). However, one of the main factors resulting in people achieving their preference for home care and death is the capability and willingness of their family/close friends to contribute to their care (Gomes and Higginson, 2006; Department 
of Health, 2008; Grande et al, 2009;

Milne and Quinn, 2009; The Scottish

Government, 2010). Care provided by

family members/friends is considered

an essential feature of healthcare

systems worldwide (Schultz, 2013; Davis

et al, 20।4). Therefore, health policy emphasises that carers need to receive adequate support throughout the patient's illness (Department of Health, 2008; The Scottish Government, 20 I0).

Family carers are also commonly referred to as 'informal carers', as the carer is not always a family member. The role is perceived as the provision of emotional support and physical care and management (National Institute for Health and Care Excellence, 2004). In the UK, there are approximately six million informal carers (The Princess Royal Trust for Carers and Royal College of General Practitioners, 2008). In Scotland, it is estimated that there are 657,300 carers who make a substantial contribution to the care of family members in the home (Buckner and Yeandle, 2007).

The majority of informal carers are women, most commonly a spouse, partner or daughter, with almost a third of all carers providing at least 20 hours per week of care (Grande et al, 1998; George, 200 I; Hudson, 2004; Visser et al, 2004; Kellehear, 2009). Informal carers have been estimated to save the UK economy $£ 87$ billion per year (Greenwood et al, 2010). Therefore, informal carers have a critical economic as well as a social role (Angelo et al, 20।3; Girgis et al, 20।4).

Although many informal carers consider the caring role as their duty, they are often unprepared for the responsibility and challenges that lie ahead (Stajduhar and Davies, 2005) and, unlike formal carers, do not always have the technical experience, knowledge and skills to provide care (Aberg et al, 2004). Added to which, many carers are elderly and have health problems themselves, which can make it difficult for them to care for another person (Carlsson and Rollison, 2003; Stajduhar, 2003; Hudson, 2004; Grande et al, 2009).
Carers of terminally ill and dying patients are faced with significant demands that can seriously impact their physical and mental health (Kelley et al, 20 13; Davis et al, 20।4; Schur et al, 20।4; Williams et al, 20|4). During any 24-hour period the tasks that carers are expected to undertake are numerous and may include supervision, decisionmaking, problem-solving, emotional support and comfort, physical care such as providing meals, moving and handling, toileting, washing, administering medications, and social care such as transportation and organising the household (Given et al, 2008; Milne and Quinn, 2009). In addition, carers may need to continue to do their paid work (Rossi Ferrario et al, 2004).

Those who lack the necessary knowledge and skills can develop feelings of uncertainty about their role and suffer increased stress and anxiety (Given et al, 2008; Grande et al, 2009). However, the level of support available to family carers is variable and not consistent (Harding and Higginson, 2003; Heyland et al, 2006; Bee et al, 2009). If informal carers are to maintain their role, they require considerable support in order to minimise the burden of providing care (Angelo et al, 20।3; Girgis et al, 20।4), be provided with support, especially to manage their own fatigue and anxiety (Harding and Higginson, 2003), and receive practical information and guidance to undertake nursing tasks (Bee et al, 2009). They also need to feel trust and confidence in the health professionals who are looking after them (Heyland et al, 2006).

There is a presumption amongst health professionals that family carers can perform the caring role adequately over a 24-hour period (Cheung and Hocking, 2004). However, despite the emotional needs and challenges facing carers being well recognised (Harding and Higginson, 2003; Hudson, 2003; Milne and Quinn, 2009), their practical support needs with respect to the provision of physical and practical care have received less attention and there is a need for more research in this area (Cheung and Hocking, 2004; Bee et al, 2009; Schultz, 2013 ). Health professionals need to have a better understanding of what it is like, from an informal carer's perspective, to care for a terminally ill relative/loved one at home and the knowledge and skills carers perceive are required to carry out that care (lo et al, 2007; Schur et al, 20 I4).

\section{Aims and objectives}

The principal aim of this study was to understand the lived experiences of carers providing care for an adult receiving palliative care at home. The particular objectives were to: explore carers' experiences about what they need to know to provide care; and explore the practical skills that carers believe they need for their role.

\section{Methods}

The research was undertaken in NHS Ayrshire \& Arran. Approval to conduct the study was provided by the West of Scotland Research Ethics Service (WosRES). A qualitative interpretative phenomenological approach was chosen, as the intention was to explore the perceptions and lived experiences of participants and the relationships emerging from the experiences (Parahoo, 2006; Polit et al, 2006; Polit and Beck, 20।0).

\section{Participants, sampling and recruitment}

Potential participants were selected by purposive sampling, a type of nonprobability sampling that is used to identify research participants at the beginning of a study (Parahoo, 2006). This type of sampling was chosen, as the study required a deliberate, hand-picked selection of people for the purpose of understanding the phenomenon and answering the research aim (Parahoo, 2006). Five GPs within NHS Ayrshire \& Arran agreed to make the first approach to potential participants. These GPs were chosen because they had obtained a postgraduate qualification in palliative medicine in the last 3-5 years and were known as GPs with a special interest in palliative care. It was anticipated that they would use their clinical experience and professional judgment to approach and select potential participants for the study. Table I shows the criteria 
that were used for selection of participants. Given the sensitivity and vulnerability of potential participants, their wellbeing, voluntary participation and informed consent were prioritised throughout the study (Wood and Ross-Kerr, 2006).

Once potential participants were identified, the GPs provided them with a brief verbal summary of the study and gave them written information. Before personal contact details were given to the researcher, each potential participant gave verbal consent to the GP to participate in the study.

Once the researcher received the contact details for the potential participant from the GP, each person was telephoned and given an overview of the study and asked if they would still be willing to take part. Each potential participant that gave their verbal consent was posted the 'Information sheet for participants' outlining the aims, objectives and purpose of the research as well as what would be involved. They were informed that written consent would be required on the day of the interview. They were also assured that their participation would be anonymous and confidential. A convenient date, time and place for the interview to take place was chosen by the participant and agreed by the researcher. Each participant was informed that they were under no obligation if later they re-considered and decided to cancel participating in the study.

\section{Data collection}

Open-ended questioning in a semistructured interview format was used to encourage freedom of expression and in-depth personal responses from

\section{Table I}

\section{Inclusion and exclusion criteria for participants}

\section{Inclusion criteria}

Adults, male and female

Aged between 18 and 80 years

English speaking

Able to understand the 'Information sheet for participants'

- Caring forlor have cared for a person who has/had been diagnosed as having cancer, cardiovascular and/or respiratory disease and in receipt of palliative care

- Unpaid carers (this can be a family member or a friend; the carer can be in receipt of state benefits to enable this role but not formally employed to be a carer for the patient)

Caring for/previously cared for a person who receives/received palliative care at home (within the last 12 months)

The patient is alive or deceased (within the last 12 months)

The patient was admitted to hospital/hospice but has been cared for at home

\section{Inclusion criteria}

Carers under the age of 18 years

Carers with learning disabilities

Carers deemed by the GP as being too vulnerable

Non-English speaking

Carers whose family member does/did not have a diagnosis of cancer, cardiovascular and/or respiratory disease or who is/was not considered to be in the palliative phase of their illness

Carers who have been bereaved longer than 12 months

participants (Wimpenny and Gass, 2000; Polit et al, 2006; LoBiondo-

Wood and Haber, 20 I0; Richards and Morse, 2013). The interview topics included how the decision was made to undertake the caring role, individual experiences of caring, the knowledge and skills of the carer and what they felt others contemplating caring for someone at home would benefit from knowing beforehand. Consent was given by each participant to record the interview in real time using a digital voice recorder. The interviews took place between December $201 \mathrm{I}$ and February 2012.

\section{Analysis}

The interviews were transcribed in full by the researcher. A thematic content analytical approach was used to analyse the transcripts. This method enabled the researcher to capture the detail in themes, identify repeated patterns that emerged from the original data and manage these themes in a systematic way (Glaser and Strauss, 1967; Burnard, 1991; Attride-Stirling, 2001 ; Patton, 2002; Braun and Clarke, 2006; Corbin and Strauss, 2008; Holloway and Wheeler, 2009).

\section{Results}

A total of 10 potential participants agreed to be contacted by the researcher. However, two decided not to take part. The remaining eight people gave verbal and written consent to be involved in the study. Three of the carers were from the same family and requested a joint interview. Therefore, a total of six interviews involving eight carers were completed. All the carers selected by the GPs were bereaved. The timescale of their involvement in caring varied from I month to II years. Information from carers' interviews on their relationship, employment status, diagnosis and length of time spent caring and the eventual place of death of the person for whom they cared is shown in Table 2.

Carers' retrospective accounts had a variety of similar experiences as well as those that were unique to their situation. The main themes and subthemes that emerged from the 


\section{Table 2}

\section{Family carer relationship, employment status, diagnosis of care recipient, time spent caring and place of death}

\begin{tabular}{|c|c|c|c|c|c|}
\hline Carer number & $\begin{array}{l}\text { Relationship to } \\
\text { the patient }\end{array}$ & $\begin{array}{l}\text { Employment } \\
\text { status while } \\
\text { caring }\end{array}$ & Diagnosis of patient/s & $\begin{array}{l}\text { Approximate } \\
\text { length of time } \\
\text { spent caring }\end{array}$ & $\begin{array}{l}\text { Place of death } \\
\text { of care recipient }\end{array}$ \\
\hline \multirow{2}{*}{$\begin{array}{l}\text { Two } \\
\text { experiences of } \\
\text { being a carer: }\end{array}$} & (I) As wife & \multirow{2}{*}{$\begin{array}{l}\text { Not employed } \\
\text { during } \\
\text { both caring } \\
\text { experiences }\end{array}$} & $\begin{array}{l}\text { Stroke and stomach cancer } \\
\text { (husband) }\end{array}$ & I I years & $\begin{array}{l}\text { Hospital } \\
\text { (husband) }\end{array}$ \\
\hline & (2) As daughter & & Bowel cancer (mother) & I year & Home (mother) \\
\hline 2 & Daughter & Employed & Lung cancer (mother) & 7 months & Home \\
\hline \multirow[t]{2}{*}{3} & \multirow[t]{2}{*}{ Daughter } & \multirow[t]{2}{*}{ Employed } & $\begin{array}{l}\text { Addison's disease, emphysema, } \\
\text { chronic obstructive pulmonary } \\
\text { disease (mother) }\end{array}$ & 2 years & Home (mother) \\
\hline & & & Dementia (father) & $\begin{array}{l}\text { Still caring for } \\
\text { father }\end{array}$ & Still alive \\
\hline 4 & Husband & Retired & Brain tumour & 4 months & Hospice \\
\hline $5^{*}$ & Daughter & Employed & $\begin{array}{l}\text { Cancer (type not known) } \\
\text { (mother) }\end{array}$ & $\begin{array}{l}1 \text { year } 6 \\
\text { months }\end{array}$ & Hospital \\
\hline $6 *$ & Daughter & Not known & & & \\
\hline $7 *$ & Son & Employed & & & \\
\hline 8 & Wife & Retired & Oesophageal cancer & I month & Home \\
\hline
\end{tabular}

analysis are illustrated in Table 3. The wording of the themes and subthemes reflect the terms and phrases most often used by carers.

\section{Knowing the right thing to do}

This theme refers to the knowledge that the carers felt was required to enable people to care for their family member at home. The theme is characterised through three subthemes: need for knowledge and practical skills; managing symptoms and administering medications; and knowing what is best for the person.

\section{Need for knowledge and practical skills}

The majority of carers found themselves undertaking the caring role for the first time in their lives. They spoke of the need for information from health professionals to enable them to understand the changes in their loved one's condition and abilities and what they could expect to happen in the future. The family group of carers had cared for their mother for a year and a half prior to her death. Their experience of caring was one of frustration and they stated that this was due to their limited knowledge and insight into their mother's condition:

\section{Table 3}

\section{Themes and subthemes that emerged from the study}

\begin{tabular}{|c|c|c|}
\hline Overall phenomenon & Main themes & Subthemes \\
\hline \multirow{2}{*}{$\begin{array}{l}\text { The nature of } \\
\text { what is involved in } \\
\text { caring: carers' lived } \\
\text { experiences of the } \\
\text { knowledge and skills } \\
\text { needed to care for } \\
\text { someone in the } \\
\text { palliative phase of } \\
\text { their illness, at home }\end{array}$} & $\begin{array}{l}\text { Knowing the } \\
\text { right thing to } \\
\text { do }\end{array}$ & $\begin{array}{l}\text { Need for knowledge and practical } \\
\text { skills } \\
\text { Managing symptoms and } \\
\text { administering medications } \\
\text { Knowing what is best for the } \\
\text { person }\end{array}$ \\
\hline & $\begin{array}{l}\text { Personal } \\
\text { experiences of } \\
\text { caring }\end{array}$ & $\begin{array}{l}\text { Impact of caring on health } \\
\text { The need to accept help } \\
\text { Experiencing a sense of satisfaction }\end{array}$ \\
\hline
\end{tabular}


'l'd liked to have knew more about, see just the general stuff...I've never seen anybody wi an illness before... we didne know what te expect an any time...it was just a kina "play it by ear"...' (C5).

Although one of the carers (C2) was herself a nurse, which meant that she had knowledge of the caring role, she had to search the internet for more information related to her mother's condition so that she could prepare herself for what would happen as her mother's illness deteriorated.

Carers could see that the person for whom they were caring was becoming more ill and frail, and would become fearful when the person's symptoms deteriorated. Many of the carers had experienced feelings of anxiety and uncertainty when faced with challenging situations and not knowing what to do or to whom to turn for answers:

'...she would take the oxygen off an fall asleep an then her breathing would get very shallow, really shallow. An that was very frightening...' (C4).

Such feelings would lead to carers feeling overwhelmed by the responsibility of caring for their loved one at home.

While most carers assumed that personal care, such as washing, dressing and toileting, was an essential part of the caring role, and one that they had to do or were expected to do, it required them to learn new skills:

'See trying te clean an adult an you've never ever done it before an all that kinda thing, an you don't know what yir daying' (C5).

The majority of carers had been apprehensive about undertaking personal care and had wanted reassurance that the way in which they were doing it was correct. Carers experienced difficulties when they were provided with pieces of equipment to use for toileting the person for whom they cared but were not shown how to use it and had to figure it out for themselves. For example, C8 described the difficulties of learning how to shave her husband's face and help him to use a urinal when his condition was such that he was confined to bed. The carers felt that they would have benefited from guidance and being shown by healthcare professionals how to perform such tasks properly in order to build their confidence in carrying out daily personal care. In addition, the carers reported that the intimacy involved with toileting care meant that their original relationship between themselves and the person for whom they cared had to be adjusted. One carer (C7) felt that toileting was too undignified for both him and his mother and therefore his sisters provided the intimate care.

When faced with lack of knowledge about what to do in a particular situation, and with no one to ask, carers would carry on regardless. Some carers would be guided by their previous life experiences or their intuition. For example, all the carers mentioned that they needed to learn how to move the person:

'It was just really the way te lift em. That was the kinda biggest point. See if you've gotta wheelchair an you're trying te lift somebody outa wheelchair, how de ye do it? De ye go te the front o them, de ye lift them that way? You're more bent than they are.Ye don't want te do an injury te yourself, or de ye go te the back and stand them up?...she had no power in her legs. You had to lift her legs up... While you're doing it you're afraid you're hurtin her...' (C4).

This carer went on to describe how he used his previous experiences as a taxi driver, where he at times had to help lift passengers, to guide him when moving his incapacitated wife.

The majority of carers stated that when they came across a problem and needed help, support and information they would turn to their family or their local primary care team. When the carers were worried about practical caring skills such as personal care, they asked for help and guidance from their community nursing team, who were seen as a valuable resource. GPs were also considered a main contact for many carers but would only visit when requested and their input was mainly in terms of the regulation of medication.

However, not all carers found accessing information and support as straightforward as they thought it would have been. They did not always know to whom to turn when they needed advice or help as there was no consistency with regard to the health professionals who visited them. The carers felt that they would have benefited from a specific contact to answer their questions. None of the carers reported that their needs had been assessed. The carers felt that an assessment of their knowledge and skills was required at the outset of their role, and that they would have benefited from a review at pertinent or appropriate intervals.

\section{Managing symptoms and administering} medications

The carers in this study often had to manage complex symptoms and medication regimes. Some carers found it difficult to keep up with the number of medications that had to be administered, the daily changes to the regime, the complexity in administration and the different times and dosage of medicines:

'Oh aye her medications. Once they gave her the sixteen tablets a day... ye had te learn the timing that was the thing, ye had te get the timing right' (C4).

Carers voiced anxieties and a lack of confidence and knowledge around recognition of changes in symptoms and the accuracy needed to administer medicines. There was particular concern when battery-operated pumps were used to deliver medication. Most of the carers indicated that they received guidance from their nursing teams on how to record the dayto-day management of medicines. However, they were anxious about the 
responsibility of administering additional doses of strong pain medication.

The family group of carers expressed that they found it difficult to understand the frequent changes in medication and were frustrated by the limited support they received from community nursing teams:

'You'd think that they'd at least be coming in te her every second day, saying "listen how's things way this medication" instead o us trying te figure it all out' (C5).

Another carer described the contradictory advice given by her mother's GP and the hospital consultant, which caused her much anxiety and stress:

'The GPs were good in some ways but I think on reflection because I communicated mainly with $\operatorname{Dr} X$ [consultant] I didn't really have a lot of confidence in their [GPs'] ability to deal with her Addison's, cause I would phone $\operatorname{Dr} X$ [consultant] and he would say right "treble her steroids" and then one time the GP came in and put them down and $\mathrm{Dr}$ $X$ [consultant] said "you might as well not bother" you know, so it was quite difficult in that way' (C3).

\section{Some carers described the} coping mechanisms they adopted to manage the administration of the daily medicines. For example, C8 wrote down the various medications that her husband had been prescribed in a notebook and ticked off every time she gave him a pill as she was concerned that he would have too much. Another carer $(\mathrm{Cl})$ kept a paper record of all the times her husband was in pain and had medication, recording the hour, date, times and effectiveness of the morphine so that the health professionals would know if the dosages needed to be altered.

Despite their concerns regarding symptom control and managing medication regimes, many of the carers valued the opportunity to administer the medication and had a sense of achievement in that it enabled their loved ones to remain at home.

\section{Knowing what is best for the person}

Each carer had an established and meaningful relationship with the person for whom they were caring. Carers repeatedly stated that they knew the person better than anyone else and knew what was best for them. Their knowledge of the person for whom they were caring meant that they were able to anticipate the negative effect of certain actions and could predict changes in behaviour:

\section{'We knew, if she knew she was terminal she'd take te her bed' (C7).}

Their care decisions, in particular ensuring that their family member remained at home for as long as possible, were driven by recognition of the importance of accomplishing the wishes of their loved one:

'...it was his wish [to be cared for and die at home] and I knew that was what he wanted' (C8).

The carers felt that part of their role was to advocate for their family member They wanted professionals to respect their knowledge of the person and their views that they were acting in the best interests of the person at the centre of the care. They also felt confident that they were making the right decisions regarding what was best for their loved one. Despite their lack of knowledge and preparedness for being a carer, they were determined to do what was best and right for their loved ones, which enabled them to accept the role of caring for their family member at home:

\section{'...we [family] kinda made the} decision over the weekend that we would take mum home...initially you don't know how long you're gonna be in that situation, whether it's gonna be six weeks or whether it's gonna be twelve weeks' (C2).

C2 was aware that her mother was keen to remain at home and wanted to make sure this occurred, as she knew that her mother would be more disorientated if she were to be moved to a hospital for the remaining days of her life. Another carer spoke about her persistence to continue to care for her husband, as she wanted to enable him to remain with a quality of life at home:

'...the skills that you learn...well... it [stroke] affected his right side, speech, everything, so we had to start from scratch get him to walk again, get him speech therapy to get him back into a rhythm with things but it was frustrating but we managed over each hurdle as time went on' (CI).

She said that as a family they had open discussions about what was needed and had made decisions together about his future care. She believed that she did the 'right thing' by him.

The close family relationship resulted in carers perceiving it to be their duty to look after their relative at home. However, acceptance of, and determination to continue in, the role was also explained as the natural thing to do for a person that one loves. Knowing what the person wanted and what was best for them made the carers more determined to continue in their caring role. Four of the people being cared for at home had their wishes honoured and died at home, while two died in hospital and one in a hospice, which had been their final preference and place of choice.

\section{Personal experiences of caring}

This theme refers to the personal experiences of looking after a loved one at home that carers wanted to share in the hope that their experiences would help others facing similar situations in the future. It is characterised by three subthemes: impact of caring on health; the need to accept help; and experiencing a sense of satisfaction.

\section{Impact of caring on health}

Many of the carers adapted their lives to cater for the increasing dependency of the person being cared for and to enable the person to remain at home. However, the caring role had an impact on their health: 
'...own health is sufferin now as l'd shut this out while caring for him' (CI).

Some carers talked about the length of time they cared for their relative and how they were confined to the home for 24 hours a day, especially during the latter stages of the person's illness. They were fearful of leaving the person alone for any length of time. They emphasised the importance of having time to themselves so that they could relax and get out of the house for a while. One carer spoke of the tiredness she felt due to the intensity of the role caring for her husband, even though she had attentive family members to help:

'...you're on your own, if you're by yourself. I'm fortunate l've got a granddaughter that did stuff for me, like shopping and stuff...or let me go out for a wee while because it really is, it's a long time, twenty four hour job and you can get quite tired' (C8).

The carers who were employed described the effect on their psychological and physical health, trying to balance work pressures with the responsibility for caring for a relative and trying to honour the person's wishes to be cared for at home:

\section{'...I'm workin, all the family was working, there was nobody that was totally available, an it was difficult...because, you think, well what about ma job, you know, what about ma colleagues an how will that go?...it was a very stressful time for me...' (C2).}

C3 was a nurse and reflected on the guilt and frustration she felt as she had to continue her busy job while at the same time support her father who had dementia to look after her mother who had multiple health issues. She was the only sibling who lived close to her parents and it had become her role to check on them daily and help her mother with personal care and do the shopping. At one time her mother was admitted to hospital and she had to share her time between the hospital, supporting her father at home as well as carrying on with her job. Such experiences led to carers feeling very anxious and stressed, which led to them becoming fatigued and subject to ill health.

\section{The need to accept help}

The carers all acknowledged that they relied on the support of their family and friends to continue their caring role and to lead as normal a life as possible:

I think people need to know that if you take a relative home you are going to be supported at home, you're not gonna be left on your own just to get on with things and I think you need to have that you need to have that support network in place probably before' (C2).

Carers recognised that there came a point when they no longer had the capability to carry out the increasing amount of care that was required. C4 described a situation where he became ill and had an admission to hospital at the same time as his wife. He had managed her personal care while she was able to help him but once her disease progressed and his health had deteriorated, he accepted the fact that he would no longer be fit enough to cope on his own. After being discharged from hospital, he knew that his wife wanted to be at home as well but he recognised that his ability was more limited than before:

'I didnae get any offer of help in the beginning, in fact she didn't want any in the beginning. An then after I come outa hospital the second time...I was ill ma self...I need help... these girls [community nurses], that's their job, an they know how te do it, an how an what te do' (C4).

\section{Another carer (C2) had been} coping with the support of family members. She had preferred to carry out the caring duties herself, as she knew what was in the best interests of her mother, who was confused. However, she too recognised that as her mother's health and mobility deteriorated, the time had come to accept help from social service carers:
'I couldn't do it on ma own...it needed two people to be able to get her up and showered certainly as it got nearer the end we did get carers to come in, in the morning just to help with showering, cause ma sister physically wasn't able to do it, cause mum wasn't, by that stage, really able to weight bear very well or walk to the shower...' (C2).

However, C2 was concerned that the carers who were paid to provide personal care for her mother were often inexperienced. She described these carers as being of benefit to herself as she had another person's view of her mother's daily condition, but a major drawback was that there was no consistency in terms of who came and having different people coming into the home exacerbated her mother's confusion and made things more difficult. When C3 became very stressed in relation to balancing her caring commitments with work, she arranged for a social carer to help her mother wash in the morning. However, both of her parents were opposed to the decision, as they wanted to retain their privacy.

Despite the problems that some carers experienced when introducing social carers into the home environment, they emphasised the importance of accepting help and reflected that they probably should have accepted help earlier.

\section{Experiencing a sense of satisfaction} Despite the negative aspects of their experiences, since the death of their spouse or parent the majority of the carers felt that they had reconciled themselves to these and expressed a sense of satisfaction for achieving what their relation wanted — to be cared for at home:

'I gotta real deep sense of satisfaction in being able to care for ma mum at home knowing that she was in her own surroundings, she was comfortable...I think she was much happier and settled in her own home than she would have been in hospital...so I think from that point 
of view I would say to people, yeh its really worth it and it's not something that, I don't think, you would regret ever doing' (C2).

Once the person had died, during moments of sadness, carers would reflect on the good times that they had experienced in the role. $\mathrm{C} 3$ referred to her experience as a 'blessing' as she now had a better knowledge of her father following her mother's death. CI looked after her husband, who had suffered from a stroke I I years previously before being diagnosed with cancer the year before he died. During that time she had also cared for her mother who had been diagnosed with cancer. When asked about her experience, she responded that it was 'very valuable' and that she had learnt a great deal:

\section{'Well, l've been there for them, tae understand what's wrong with them, dealing wi the situation together...teaching them new things altogether...you've got to be in that situation to understand what you're doing for them...but the experiences are hard...I would nae change it for anything' $(\mathrm{Cl})$.}

Not all carers though felt that the experience had been valuable. The family of carers spoke of the suffering that their mother endured during her last 6 months and at the end of life and the lack of support that they received. Therefore, when wishes were not achieved and the person died in a way that was not expected then there was a lasting sense of guilt and regret felt by carers. Nevertheless, the majority did experience a strong sense of personal satisfaction when they reflected on their experience of caring for their family member at home.

\section{Discussion}

\section{Making the decision to care for a terminally ill loved} one at home

The carers in this study were determined to take on the caring role, as they wanted to honour the wishes of their family member to be cared for and die at home. They repeatedly stated that they knew the person well enough to know what was best for the person, which in the majority of cases was to remain at home. Although many carers felt a sense of obligation to care for their family member at home, the decision to become a home carer was mainly influenced by love of their family member.

The reasoning behind the decision to care for a terminally ill person at home has been given some attention in the literature. For example,

Stajduhar and Davies (2005) aimed to understand the variations in and factors influencing family members' decisions to provide home-based palliative care. They collected data from participant observations and in-depth interviews with 13 family members providing care to a person with palliative care needs at home, 47 bereaved family members and 25 healthcare providers. They found that some caregivers made uninformed decisions and gave little consideration to the implications of caring for loved ones with a terminal illness at home. Some reluctantly agreed to provide care at home, while others were keen to undertake the role. The decision to care for a loved one at home was influenced by carers' previous negative experiences of institutional care and, like the carers in the current study, wanting to fulfil a promise to the patient to be cared for at home and maintain as normal a family life as possible. Jo et al (2007) undertook a qualitative face-to-face interview study to explore the perspectives of 10 dyads of spousal caregivers and care recipients on the caregiving experience in home-based palliative care. They found that the majority of informal carers considered caregiving as an extension of the family relationship.

Concerns have been voiced that the emphasis on caring for terminally ill and dying patients in the home environment may result in some family members feeling obligated to provide home care (Stajduhar, 2003). According to Brobäck and Berterö (2003), family carers must not feel pressurised into taking on the caring role and the decision to be a caregiver should be informed and voluntary. When making decisions to care for a terminally ill person at home, carers need to understand the illness, its inevitable impact and what to expect in the future (McPherson et al, 200l; Hasson et al, 2009). That way carers will be better prepared for their role and will be enabled to make an informed choice to either provide care at home or consider alternative care options (McPherson et al, 200 I; Stajduhar and Davies, 2005; Docherty et al, 2008; Hasson et al, 2009; Stajduhar and Cohen, 2009).

\section{The need for knowledge, practical skills and support} One of the main findings of this study was that although the carers had expert knowledge of the person for whom they were caring, they lacked knowledge of their loved one's condition and the skills required to care for them, which left them feeling unprepared for the role. Many of the carers in this study found themselves undertaking the caring role for the first time. Each carer had a different situation and, therefore, their information and knowledge needs were not the same. However, none of the carers reported being assessed at the outset of their caring role regarding their knowledge and skills and what they understood regarding their loved one's condition and the changes to expect. Such findings have been reflected in the wider literature (Brobäck and Berterö, 2003; Harding and Higginson, 2003; Husdon, 2004; Visser et al, 2004; Gomes and Higginson, 2006; Osse et al, 2006; Hudson et al, 2008; Hasson et al, 2009).

The carers in this study were reliant on their primary care teams for support to maintain their loved one's care at home, particularly community nurses and GPs. However, community services were not always available at the times when they were experiencing difficulties and consequently they felt unsupported. Primary healthcare teams, i.e. community nurses and GPs, are mostly responsible for providing information and support to patients and their carers (Brobäck and Berterö, 2003; Greenwood et al, 20l0). Despite the aim of palliative care being to support the relatives of terminally ill people (World Health Organization, 20l2), it has been consistently shown that many family caregivers have a variety of unmet 
needs and receive minimal guidance and support from professionals about the caring role, e.g. what care will be needed, how long it will be required, and how to access or request the services that are available to them (Hudson, 2004; Osse et al, 2006; Given et al, 2008; Bee et al, 2009; Hasson et al, 2009; Angelo and Egan, 2014).

Some primary care teams have been found to be ill-equipped to provide holistic support for terminally ill people being cared for at home (Fitzsimons et al, 2007). Greenwood et al (2010) conducted a survey to identify GPs' attitudes, awareness and knowledge of the issues facing informal carers, the services offered within general practice and the barriers to supporting carers. A self-completion questionnaire was distributed to 95 GPs from a variety of areas in England. The response rate was $82 \%$ ( $n=78)$. The GPs identified that, although they assessed carers for emotional and physical health problems and financial and isolation difficulties, time, resources and lack of knowledge acted as barriers to providing support to carers. In addition, 89\% felt they had insufficient training in supporting carers and $47 \%$ lacked confidence that they were meeting carers' needs. Therefore, the researchers concluded that, given the greater commissioning role for primary care, further investigation is needed to determine how best to train and facilitate GPs in their role in supporting carers.

The carers in this study expressed that as well as needing more knowledge about their loved one's condition they also required support and guidance to carry out some of the necessary daily practical duties associated with the caring role. In particular, they mentioned that they needed education relating to lifting and handling, personal care such as washing and shaving and how to use toileting equipment. It has been found elsewhere in the literature that carers lack knowledge and skills in relation to personal care, incontinence care and how to use equipment associated with caring (Hudson, 2004; Osse et al, 2006; Fitzsimons et al, 2007; Bee et al, 2009; Burt et al, 20 I0). With regard to moving and handling, nurses have to attend mandatory training provided by their employers and have access to skilled expert advisors who can recommend knowledge and resources for safe practice (Health and Safety Executive, 2014). However, in this study, it was apparent that there had been no dissemination of such knowledge from nurse to carer.

Bee et al's (2009) systematic review relating to the information needs of informal caregivers providing palliative and end-of-life care to people with advanced cancer at home, found that research consistently highlights lack of practical support and information which resulted in carers adopting a trial-and-error approach to practical nursing skills when caring for loved ones at the end of life. Bee et al concluded that home-based palliative care services have not been sufficiently focused on helping informal caregivers acquire practical nursing skills and that access to professional advice and skillsbased training is a potentially effective method of increasing carers' confidence in their ability to undertake practical aspects of home-based care.

Lack of support can result in carers not being able to continue in their caring role and lead to crisis admissions to hospital of terminally ill and dying patients (Stuart, 2003; Stoltz et al, 2004; Given et al, 2008). Timely access to advice, information and support and regular assessment have been shown to have a positive influence on informal carers' experience of caring and ability to maintain their role (Harding and Higginson, 2003; Stajduhar, 2003; Fitzsimons et al, 2007; Given et al, 2008). Therefore, the needs of informal carers need to be assessed and managed regularly rather than only occurring during periods of crisis (Grande et al, 2009).

A variety of methods are used to provide information to and support for patients and their informal carers, including written material, telephone helplines, teaching, audiovisual aids and patient group educational programmes (McPherson et al, 200l;
Hudson et al, 2008; White et al, 2008). Individually tailored education and support programmes rather than uniform interventions may improve carers' confidence, competence and preparedness for the caring role and result in better quality of life for patients being cared for at home (McPherson et al, 200 I; Gomes and Higginson, 2006; White et al, 2008; Schildmann and Higginson, 20 I I).

However, despite researchers giving considerable attention to the information and support needs of family caregivers, the effectiveness of individual interventions for caregivers in terms of how they translate into improved caregiver skills and better outcomes for both the carer and the patient is not well understood (McPherson et al, 200 I; Farren et al, 2004; Epiphaniou et al, 2012; Simonic et al, 20।2). For example, it has been found that although support and educational interventions can have a positive effect on caregiver experience (Hudson et al, 2005), they may not necessarily reduce a carer's anxiety or stress levels (McPherson et al, 200 I; Cheung and Hocking, 2004; Hudson et al, 2005). Therefore, further research is required regarding the best methods for providing interventions for carers (Hudson, 2003; Farren et al, 2004; Given et al, 2008; Grande et al, 2009; Schildmann and Higginson, 20 I I).

\section{Symptom management and medication regimes}

The carers in this study voiced anxieties and fears about their lack of knowledge with regard to managing complex symptoms and being responsible for medication regimes. The management of pain and other symptoms at the end of life has been identified as a particular area of caregiver burden (Terry et al, 2006; Anderson and Kralik, 2008; Docherty et al, 2008; Burt et al, 2010 ; Kelley et al, 2013 ; Sheehy-Skeffington et al, 20|4). Terminally ill patients being cared for at home can experience poor management of their symptoms, such as pain, nausea and breathlessness, which can lead to heightened distress for both patients and caregivers (Burt et al, 20।0). Patients and their 
carers have been found to experience variations in terms of receiving support to manage end-of-life symptoms from specialist palliative care and district nurses and GPs (Fitzsimons et al, 2007; Burt et al, 20।0).

If palliative care patients are to be cared for and die at home, their symptoms need to be adequately controlled so as to prevent crisis admissions to hospitals (Kelley et al, 20। 3; Sheehy-Skeffington et al, 20 I 4). As part of a study exploring the concerns of terminally ill patients and their families, Terry et al (2006) conducted a focus group with 18 bereaved carers of patients who had been under a palliative care service. The carers recalled problems accessing services and support and had needed more help with practical issues such as medication timing and dose. They believed that they had not been provided with enough information about their loved ones' illness and symptoms.

Like the carers in the current study, the majority of informal carers have been found to be willing to assume responsibility for medication administration, as it enables their loved ones to remain at home (Anderson and Kralik, 2008; Sheehy-Skeffington et al, 20|4). However, it needs to be ensured that informal caregivers can safely manage medications to alleviate pain and distressing symptoms in patients near the end of life (Joyce and Lau, 20 I 3). Effective symptom control is often directly linked to medication management and relies on access to medications at all times, including out of hours (Anderson and Kralik, 2008). To help medication management in the home environment, informal carers need to be provided with education to increase their knowledge of medications commonly used at the end of life and the existing medication management process needs to be supported or simplified (Joyce and Lau, 20|3).

In an Australian study, Anderson and Kralik (2008) explored the feasibility of providing carers with 'pre-drawn up' subcutaneous syringes of medication, that they kept in the home refrigerator and which they administered to their loved one in order to relieve symptoms such as pain and nausea. They conducted semi-structured interviews with 14 carers who were administering pre-drawn up medications in the home setting. The carers highly valued the practice as it enabled them to provide immediate symptom relief and empowered them in their caring role. After their loved ones had died, the carers expressed a sense of pride and achievement from administering medications in this way because they had been able to care for their loved ones and enable them to die at home. However, the security and ethical issues associated with the presence of certain medications in the home and the education required to enable the carer to administer subcutaneous injections would need consideration.

The carers in Anderson and Kralik's study had access to a 24-hour telephone support service, which they found essential in helping them with their symptom management decisions. McCall et al (2008) claimed that developments in information technology and tele-care systems could be used to help monitor the symptoms of palliative care patients remotely, improve communication with patients and their family carers, reduce demands on over-stretched health services, and enable symptoms to be reported as they are happening, thus enhancing symptom management.

\section{Impact of caring on health}

Many of the carers in this study reflected that although they were determined to enable their family member to remain at home, they found that the strain of the caring role had a detrimental effect on their health.

Although caregivers are essential in the provision of home-based palliative care, they are often unprepared for a role that is very physically and emotionally demanding (Angelo and Egan, 20।4). Caring for a loved one at the end of life has been found to be more intense and burdensome than in other caregiver groups and informal carers of terminally ill and dying patients have been found to experience higher levels of ill health than carers of people with a chronic or long-term illness or carers providing short-term care (Williams et al, 20|4). Caregiver distress can be exacerbated when the care recipient is clinically unstable, depressed and has cognitive impairment (Hirdes et al, 20 I2).

In Jo et al's (2007) qualitative interview study exploring the experience of caregivers and care recipients in home-based palliative care, spousal caregivers identified many negative reactions to caregiving, including fatigue, weariness, depression, anger and sadness. In addition, the care recipients were very concerned about the stress that caring for them placed on their spouses. Although caregivers and care recipients were generally positive about the support they received, they experienced difficulties in communication with service providers and poor coordination of care among the various services. Lack of consistency and continuity in the provision of supportive services and fragmented care can increase carers' anxiety and stress and exacerbate carers' physical and psychological ill-health (Stajduhar, 2003; Cheung and Hocking, 2004; Osse et al, 2006; Fitzsimons et al, 2007; Gallagher-Thompson and Coon, 2007; Given et al, 2008; Grande et al, 2009; Burt et al, 20 10; Greenwood et al, 20।0; Angelo and Egan, 20।4).

In the current study, some carers expressed concerns about leaving their loved one, even though they recognised and acknowledged the benefits of having a short break. People in the end stages of their diseases tend to become increasingly dependent on their family caregiver for emotional and physical support, which can lead to caregivers not being able to leave their loved one and social isolation (Hudson, 2004; Fitzsimons et al, 2007; Hasson et al, 2009). Community palliative care health professionals have identified that one of the main priorities for supporting family caregivers is encouraging them to care for themselves and to take time out from the caring role (Angelo et al, 20|3). 
Stoltz et al (2004) found that informal carers require knowledge of how to access respite services and peer support groups. However, one of the carers in the current study stated that she had tried to get her parents to accept a social carer in order to take some of the strain from herself but that her parents would not accept an outsider coming into the house. Caregivers, therefore, may need support from health professionals when encouraging the care recipient to accept formal care (Aberg et al, 2004).

\section{Positive elements of the caring role}

Despite the problems they experienced, the majority of the carers stated that they felt a sense of satisfaction since the death of their spouse or parent. Although much research has highlighted the negative aspects of caring for a terminally ill or dying loved one at home, it has also been found that caring for a loved one can result in lifeenriching experiences for many carers and strengthened relationships between the carer and care recipient (Stajduhar, 2003; Jo et al, 2007).

\section{Wong and Ussher (2009)} undertook a qualitative interview study of 22 bereaved informal carers who had looked after a family member with cancer at home. The aim was to explore the positive aspects associated with providing care in a palliative context at home. The carers expressed that despite the associated emotional stress and strains of the caring role, it was very rewarding to do something good for their loved one and be able to meet their needs. They also felt that the relationship between them and their loved one had been strengthened. Being present at the point of death was considered particularly rewarding as it enabled them to say goodbye, was a spiritual experience and provided closure. The positive meanings that they associated with the caring role and being closely involved in the dying process helped them with their sense of loss after their loved one's death. Therefore, being able to perceive positive experiences in relation to caring for a loved one at home may help carers throughout their caring role and in their bereavement (Hudson, 2004; Hudson et al, 2005; Epiphaniou et al 20।2).

\section{Recommendations}

- Preparation: Carers need to be prepared for what the caregiving role will entail before making a decision to care for a loved one at home. In particular, they need to understand the nature of the person's condition, the changes to expect as the person's condition deteriorates, and the potential demands of the role.

- Knowledge: Carers require information and education throughout the entire time they care for their loved one, in a format that they can understand. As well as information on how best to care for their loved one, they need to know to whom to turn when they experience problems. They also need to be informed about what to expect as their loved one's health declines and the signs and symptoms of approaching death. Gaps in carers' knowledge need to be assessed and addressed by the professionals involved so that carers are adequately prepared and equipped for their role. In addition, carers need to be respected and valued for their unique knowledge of the person and providing a vital 24-hour contribution to the terminally ill person's care.

" Skills: Carers will often need practical nursing skills. Therefore, professionals need to ascertain the knowledge, capability and competence of carers with regard to personal cleansing and toileting, moving and handling techniques and managing and administering medications. Carers' abilities should be assessed and skills taught on an individual basis.

- Support: Carers need access to timely support and consistency in terms of community services and professionals. They need to know that they will receive support when it is needed, such as practical and physical help, and that they can have a break from their duties, even if it is only to do their shopping.
Professionals involved need to be proactive in anticipating the resources that may be required by carers, should problems arise. Carers need emotional support in the form of someone to listen to their worries and be supported to access respite care. It is important that a sensitive assessment is undertaken and reviewed at pertinent intervals and that carers are assessed with regard to their ability to continue their role, particularly if they are suffering from ill-health themselves.

- Further research: More research is required to improve understanding of carers' needs and the interventions that can help them undertake their role. Professionals and policy makers must work together in this endeavour in order to provide the appropriate support for carers, so that care recipients can spend the entire duration of their final illness at home, if that is their wish.

\section{Limitations of the study}

There are a number of limitations associated with this study:

- First, the researcher was the main collector and analyser of the data and therefore the results are limited by the researcher's subjective interpretation (Parahoo, 2006; LoBiondo-Wood and Haber, 2010). Every effort was made to counteract subjectivity by validating the categories and themes with experienced colleagues who were not involved in the study.

- Second, a purposive sampling approach was chosen to ensure rich data collection from a manageable population of subjects. However, this sampling method introduces the potential for bias and the data collected may not be representative of the wider population of caregivers of people with palliative care needs (Polit et al, 2006).

- Third, the sample was small in that only eight caregivers were recruited and participated, three of whom were from the same family and wanted to be interviewed together (LoBiondo and Haber, 20l0). 
- Fourth, all those who participated were bereaved carers (rather than currently active) and therefore their accounts were retrospective and dependent on their ability to recall accurate details (Addington-Hall and McPherson, 200I).

\section{Conclusion}

This study has provided considerable insight into the care that families provide to enable their loved ones to remain at home at the end of their life. It was apparent that the sustainability of home care is fragile as spousal carers are of similar age as the terminally ill care recipient and often have their own health issues, which may be exacerbated by the burden of their caring responsibilities. Adult children who are carers often have work commitments and family responsibilities, which can make the caregiving role a very stressful experience. In addition, the duration of the care provision at home has no definitive timescale, as some people survive longer than their disease trajectory predicts.

The study supports the wider literature by demonstrating that carers play a vital role in supporting people with life-limiting illnesses to remain at home and need specific knowledge and skills at different points over the duration of their role. Professionals need to include and understand the needs of carers so that the whole experience of caring for someone with palliative care needs in the home can be made easier and less distressing. The carer's role needs to be valued by professionals and carers must be provided with the necessary understanding and support to alleviate their anxieties and concerns.

\section{Carers have the potential to} benefit from their experiences of caring, but that can only occur if they are provided with emotional and physical support. Professionals need to appreciate that some carers are better equipped or prepared for the caring role than others because of previous experiences. Ultimately, carers need to know that they are cared for and that their own needs will be met. EOLJ

\section{References}

Aberg AC, Sidenvall B, Hepworth M, O'Reilly K, Lithell H (2004) Continuity of the self in later life: perceptions of informal caregivers. Qualitative Health Research 14(6): 792-815

Addington-Hall J, McPherson C (2001) After-death interviews with surrogates/ bereaved family members: some issues of validity. Journal of Pain and Symptom Management 22(3): 784-90

Anderson BA, Kralik D (2008) Palliative care at home: carers and medication management. Palliative \& Supportive Care 6(4): 349-56

Angelo J, Egan R (2014) Family caregivers voice their needs: a photovoice study. Palliative \& Supportive Care 20 May: 1-12 [Epub ahead of print]

Angelo JK, Egan R, Reid K (2013)

Essential knowledge for family caregivers: a qualitative study. International Journal of Palliative Nursing 19(8): 383-8

Attride-Stirling J (2001) Thematic networks: an analytical tool for qualitative research. Qualitative Research 1(3): 385-405

Beccaro M, Costantini M, Giorgi Rossi P, Miccinesi G, Grimaldi M, Bruzzi P; ISDOC Study Group (2006) Actual and preferred place of death of cancer patients. Results from the Italian survey of the dying of cancer (ISDOC). Journal of Epidemiology and Community Health 60(5): 412-16

Bee PE, Barnes P, Luker KA (2009) A systematic review of informal caregivers' needs in providing home-based end-oflife care to people with cancer. Journal of Clinical Nursing 18(10): 1379-93

Braun V, Clarke V (2006) Using thematic analysis in psychology. Qualitative Research in Psychology 3(2): 77-101

Brobäck G, Berterö C (2003) How next of kin experience palliative care of relatives at home. European Journal of Cancer Care 12(4): 339-46

Buckner L, Yeandle S (2007) Valuing Carers - Calculating the Value of Unpaid Care. Carers UK, London. http://www.sociology. leeds.ac.uk/assets/files/research/circle/valuingcarers.pdf (last accessed 24 June 2014)

Burnard P (1991) A method of analysing interview transcripts in qualitative research. Nurse Education Today 11(6): 461-6

Burt J, Shipman C, Richardson A, Ream E, Addington-Hall J (2010) The experiences of older adults in the community dying from cancer and non cancer causes: a national survey of bereaved relatives. Age and Ageing 39(1): 86-91

Carlsson ME, Rollison B (2003)

A comparison of patients dying at home and patients dying at a hospice: sociodemographic factors and caregivers experiences. Palliative \& Supportive Care 1(1): 33-9
Cheung J, Hocking P (2004) Caring as worrying: the experience of spousal carers. Journal of Advanced Nursing 47(5): 475-82 Corbin J, Strauss A (2008) Basics of Qualitative Research: Techniques and Procedures for Developing Grounded Theory. 3rd edn. Sage Publications, London

Davis EL, Deane FP, Lyons GC (2014) Acceptance and valued living as critical appraisal and coping strengths for caregivers dealing with terminal illness and bereavement. Palliative \& Supportive Care 30 April: 1-10 [Epub ahead of print] Department of Health (2008) End of Life Care Strategy: Promoting High Quality Care for all Adults at the End of Life. The Stationery Office, London

\section{Key Points}

\ Informal carers of people with terminal illness play an essential role in enabling people to die at home.

\ Carers need to be better prepared for the caring role and understand the implications and potential burden of agreeing to care for their loved one at home.

\ Informal carers of people at the end of life are at risk of physical and psychological ill health.

\ Informal carers require knowledge and practical caring skills in order to maintain their role.

\) Carers can find managing complex end-of-life care medication regimes challenging.

>) Professionals need to understand the needs of carers and support them throughout the period of care so that the whole experience of caring for a loved one with palliative care needs is improved.

\) With adequate care and support, caring for a loved one at the end of life can be a positive experience for informal carers. 
Docherty A, Owens A, Asadi-Lari M, Petchey R, Williams J, Carter YH (2008) Knowledge and information needs of informal caregivers in palliative care: a qualitative systematic review. Palliative Medicine 22(2): 153-71

Epiphaniou E, Hamilton D, Bridger S et al (2012) Adjusting to the caregiving role: the importance of coping and support. International Journal of Palliative Nursing 18(11): 541-5

Farren CJ, Loukissa D, Perraud S, Paun O (2004) Alzheimer's disease caregiving information and skills. Part II: family caregiver issues and concerns. Research in Nursing \& Health 27(1): 40-51

Fitzsimons D, Mullan D, Wilson J et al (2007) The challenge of patients' unmet palliative care needs in the final stages of chronic illness. Palliative Medicine 21(4): 313-22

Gallagher-Thompson D, Coon DW (2007) Evidence-based psychological treatments for distress in family caregivers of older adults. Psychology and Ageing 22(1): 37-51

Gao W, Ho YK, Verne J, Glickman M, Higginson IJ; GUIDE_Care project (2013) Changing patterns in place of cancer death in England: a population-based study. PLoS Medicine 10(3): el001410. doi: 10.1371/ journal.pmed.1001410

George M (2001) It Could Be You: a Report on the Chances of Becoming a Carer. Carers UK, London

Girgis A, Abernethy AP, Currow DC (2014) Caring at the end of life: do cancer caregivers differ from other caregivers? BMJ Supportive \& Palliative Care 22 January. doi: 10.1136/bmjspcare-2013-000495 [Epub ahead of print]

Given B, Sherwood PR, Given CW (2008) What knowledge and skills do caregivers need? American Journal of Nursing 108(9, Suppl): 28-34

Glaser B, Strauss AL (1967) The Discovery of Grounded Theory: Strategies for Qualitative Research. Aldine, New York

Gomes B, Higginson IJ (2006) Factors influencing death at home in terminally ill patients with cancer: systematic review. British Medical Journal 332(7540): 515-21

Gomes B, Calanzani N, Gysels M, Hall S, Higginson IJ (2013) Heterogeneity and changes in preferences for dying at home: a systematic review. BMC Palliative Care 12: 7. doi: 10.1186/1472-684X-12-7

Grande GE, Addington-Hall JM, Todd CJ (1998) Place of death and access to home care services: are certain patient groups at a disadvantage? Social Science $\mathcal{E}$ Medicine 47(5): 565-79

Grande G, Stajduhar K, Aoun S et al (2009) Supporting lay carers in end of life care: current gaps and future priorities. Palliative Medicine 23(4): 339-44
Greenwood N, Mackenzie A, Habibi R, Atkins C, Jones R (2010) General practitioners and carers: a questionnaire survey of attitudes, awareness of issues, barriers and enablers to provision of services. BMC Family Practice 11: 100. doi: 10.1186/1471-2296-11-100

Harding R, Higginson IJ (2003) What is the best way to help caregivers in cancer and palliative care? A systemic literature review of interventions and their effectiveness. Palliative Medicine 17(1): 63-74

Hasson F, Spence A, Waldron M, Kernohan G, McLaughlin D, Watson B, Cochrane B (2009) Experiences and needs of bereaved carers during palliative and end-of-life care for people with chronic obstructive pulmonary disease. Journal of Palliative Care 25(3): 157-63

Health and Safety Executive (2014) Manual Handling in Health and Social Care. Health and Safety Executive, London. http://www hse.gov.uk/healthservices/moving-handling. htm (last accessed 24 June 2014)

Heyland DK, Dodek P, Rocker G et al (2006) What matters most in end-of-life care: perceptions of seriously ill patients and their family members. Canadian Medical Association Journal 174(5): 627-33

Hirdes JP, Freeman S, Smith TF, Stolee P (2012) Predictors of caregiver distress among palliative home care clients in Ontario: evidence based on the interRAI Palliative Care. Palliative E Supportive Care 10(3): 155-63

Holloway I, Wheeler S (2009) Qualitative Research in Nursing. 3rd edn. WileyBlackwell, Oxford

Hudson P (2003) A conceptual model and key variables for guiding supportive interventions for family caregivers of people receiving palliative care. Palliative $\mathcal{E}$ Supportive Care 1(4): 353-65

Hudson P (2004) Positive aspects and challenges associated with caring for a dying relative at home. International Journal of Palliative Nursing 10(2): 58-65

Hudson PL, Aranda S, Hayman-White K (2005) A psycho-educational intervention for family carergivers of patients receiving palliative care: a randomized control trial. Journal of Pain and Symptom Management 30(4): 329-41

Hudson P, Quinn K, Kristjanson L, Thomas T, Braithwaite M, Fisher J, Cockayne M (2008) Evaluation of a psycho-educational group programme for family caregivers in home-based palliative care. Palliative Medicine 22(3): 270-80

Jo S, Brazil K, Lohfeld L, Willison K (2007) Caregiving at the end of life: perspectives from spousal caregivers and care recipients. Palliative E Supportive Care 5(1): 11-7

Joyce BT, Lau DT (2013) Hospice experiences and approaches to support and assess family caregivers in managing medications for home hospice patients: a providers survey. Palliative Medicine 27(4): 329-38

Kellehear A (2009) Understanding the social and cultural dimensions of family caregiving. In: Hudson P, Payne $\mathrm{S}$, eds. Family Carers in Palliative Care: a Guide for Health and Social Care Professionals. Oxford University Press, Oxford: 21-36

Kelley M, Demiris G, Nguyen H, Oliver DP, Wittenberg-Lyles E (2013) Informal hospice caregiver pain management concerns: a qualitative study. Palliative Medicine 27(7): 673-82

LoBiondo-Wood G, Haber J, eds (2010) Nursing Research: Methods and Critical Appraisal for Evidence-based Practice. Mosby Elsevier, St Louis, MO

McCall K, Keen J, Farrer K et al (2008)

Perceptions of the use of a remote monitoring system in patients receiving palliative care at home. International Journal of Palliative Nursing 14(9): 426-31

McPherson CJ, Higginson IJ, Hearn J (2001) Effective methods of giving information in cancer: a systematic literature review of randomized controlled trials. Journal of Public Health Medicine 23(3): 227-34

Milne D, Quinn K (2009) Family carers of people with advanced cancer. In: Hudson P, Payne S, eds. Family Carers in Palliative Care: a Guide for Health and Social Care Professionals. Oxford University Press, Oxford: 211-30

National Institute for Health and Care Excellence (2004) Improving Supportive and Palliative Care for Adults with Cancer: the Manual. NICE, London

O'Brien M, Jack B (2010) Barriers to dying at home: the impact of poor co-ordination of community service provision for patients with cancer. Health $\&$ Social Care in the Community 18(4): 337-45

Osse BH, Vernooij-Dassen MJ, Schadé E, Grol RP (2006) Problems experienced by the informal caregivers of cancer patients and their needs for support. Cancer Nursing 29(5): 378-88

Parahoo K (2006) Nursing Research: Principles, Process and Issues. 2nd edn. Palgrave Macmillan, Basingstoke, Hampshire

Patton M (2002) Qualitative Research $\mathcal{E}$ Evaluation Methods. 3rd edn. Sage Publications, London

Polit DF, Beck C (2010) Essentials of Nursing Research: Appraising Evidence for Nursing Practice. 7th edn. Lippincott Williams and Wilkins, Philadelphia

Polit DF, Beck CT, Hungler BP (2006) Essentials of Nursing Research: Methods, Appraisal and Utilization. 6th edn. Lippincott Williams and Wilkins, Philadelphia 
Richards L, Morse JM (2013) Read Me First for a User's Guide to Qualitative Methods. Sage Publications, London

Rossi Ferrario S, Cardillo V, Vicario F, Balzarini E, Zotti AM (2004) Advanced cancer at home: caregiving and bereavement. Palliative Medicine 18(2): 129-36

Schildmann EK, Higginson IJ (2011)

Evaluating psycho-educational interventions for informal carers of patients receiving cancer care or palliative care: strengths and limitations of different study designs. Palliative Medicine 25(4): 345-56

Schulz R (2013) Research priorities in geriatric palliative care: informal caregiving Journal of Palliative Medicine 16(9): 100812

Schur S, Neubauer M, Amering $\mathrm{M}$ et al (2014) Validation of the Family Inventory of Needs (FIN) for family caregivers in palliative care. Palliative \& Supportive Care 20 May: 1-7 [Epub ahead of print]

Sheehy-Skeffington B, McLean S, Bramwell M, O'Leary N, O'Gorman A (2014) Caregivers' experiences of managing medications for palliative care patients at the end of life: a qualitative study. The American Journal of Hospice \& Palliative Care 31(2): 148-54

Simonic A, Furlan M, Ravnjak T, Dirkse D (2012) Caring for caregivers: a right way to do it? Current Opinion in Supportive and Palliative Care 6(3): 379-85

Stajduhar K (2003) Examining the perspectives of family members involved in the delivery of palliative care at home. Journal of Palliative Care 19(1): 27-35
Stajduhar K, Cohen R (2009) Family caregiving in the home. In: Hudson P, Payne S, eds. Family Carers in Palliative Care: a Guide for Health and Social Care Professionals. Oxford University Press, Oxford: 149-68

Stajduhar K, Davies B (2005) Variations in and factors influencing family members decisions for palliative home care. Palliative Medicine 19(1): 21-32

Stoltz P, Udén G, Willman A (2004) Support for family carers who care for an elderly person at home - a systemic literature review. Scandinavian Journal of Caring Sciences 18(2): 111-19

Stuart B (2003) Transition management: a new paradigm for home care of the chronically ill near the end of life. Home Health Care Management \& Practice 15(2): 126-35

Terry W, Olson LG, Wilss L, Boulton-Lewis G (2006) Experience of dying: concerns of dying patients and of carers. International Medicine Journal 36(6): 338-46

The Princess Royal Trust for Carers, Royal College of General Practitioners (2008) Supporting Carers: an Action Guide for General Practitioners and Their Teams. 2nd edn. The Princess Royal Trust for Carers, Royal College of General Practitioners, London. http://www.rcgp.org.uk/ /media/ Files/CIRC/Carers/Carers-Action-Guide. ashx (last accessed 24 June 2014)

The Scottish Government (2010) Caring Together: the Carers Strategy for Scotland 2010-2015. The Scottish Government, Edinburgh

Thomas C, Morris SM, Clark D (2004)
Place of death: preferences among cancer patients and their carers. Social Science $E$ Medicine 58(12): 2431-44

Visser G, Klinkenberg M, Broese van Greoenou M, Willems DL, Knipscheer CP, Deeg DJ (2004) The end of life: informal care for dying older people and its relationship to place of death. Palliative Medicine 18(5): 468-77

White K, D'Abrew N, Auret K, Graham N, Duggan G (2008) Learn Now; Live Well: an educational programme for caregivers. International Journal of Palliative Nursing 14(10): 497-501

Williams AM, Wang L, Kitchen P (2014) Differential impacts of care-giving across three caregiver groups in Canada: end-oflife care, long-term care and short-term care. Health \& Social Care in the Community 22(2): 187-96

Wimpenny P, Gass J (2000) Interviewing in phenomenology and grounded theory: is there a difference? Journal of Advanced Nursing 31(6): 1485-92

Wong WK, Ussher J (2009) Bereaved informal cancer carers making sense of their palliative care experiences at home. Health and Social Care in the Community 17(3): 274-82

Wood M, Ross-Kerr J (2006) Basic Steps in Planning Nursing Research: From Question to Proposal. 6th edn. Jones and Bartlett, London

World Health Organization (2012) WHO Definition of Palliative Care. WHO,

Geneva. http://www.who.int/cancer/ palliative/definition/en/ (last accessed 24 June 2014) 